\title{
Manganese Catalyzed Anti-Markovnikov Hydroamination of Allyl Al- cohols via Hydrogen Borrowing Catalysis
}

\author{
Kuhali Das, ${ }^{\mathrm{a}}$ Koushik Sarkar, ${ }^{\mathrm{a}}$ and Biplab Maji ${ }^{\mathrm{a} *}$

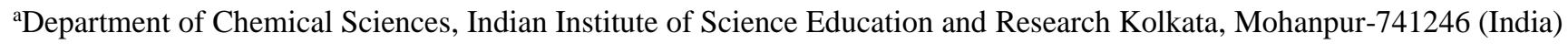 \\ KEYWORDS. Hydroamination, $\gamma$-amino alcohol, borrowing hydrogen catalysis, manganese, phosphine-free.
}

\begin{abstract}
Controlling the selectivity in hydroamination reaction is an extremely challenging yet highly desirable task for the selective diversification of amines. In this manuscript, a selective formal anti-Markovnikov hydroamination of allyl alcohols is presented. It enables the versatile synthesis of valuable $\gamma$-amino alcohol building blocks. A phosphine-free Earth's abundant manganese(I) complex catalyzed the reaction under hydrogen borrowing conditions. A vast range of aliphatic, aromatic amines, drug molecules, and natural product derivatives underwent successful hydroamination with primary and secondary allylic alcohols with excellent functional group tolerance (57 examples). The catalysis could be performed on a gram scale and have been applied for the synthesis of drug molecules. The mechanistic studies revealed the metal-ligand bifunctionality as well as hemilability of the ligand backbone as the key design principle for the success of this catalysis.
\end{abstract}

Hydroamination of unsaturated C-C bonds offers the homologation of valuable amine building blocks to higher congeners. ${ }^{1}$ However, the core issues of concern lie in the selective formation of either Markovnikov or anti-Markovnikov adducts. In this regard, hydroamination of terminal alkene mostly delivers Markovnikov products thanks to innate stereoelectronics of the reacting alkene and amine substrates. ${ }^{\text {a-c, } 2}$ The anti-Markovnikov hydroamination, on the other hand, is highly challenging and mostly driven either by modulating the substrates and catalytic conditions or by multi-step formal synthesis. ${ }^{\text {c, }, 2 \mathrm{a}-\mathrm{h}, 3}$ In particular, the anti-Markovnikov hydroaminations of readily available allyl alcohols, which allowed the synthesis of $\gamma$-amino alcohols, are rare. ${ }^{4}$

$\gamma$-Amino alcohols are versatile synthetic intermediates for many pharmaceuticals and bioactive molecules (some of them are exemplified in Scheme 1a). ${ }^{5}$ Traditional procedures for their synthesis include hydroamination of $\alpha, \beta$-unsaturated carbonyl compounds followed by hydrogenation, reduction of preformed $\beta$-amino carbonyls, ${ }^{6}$ and $\mathrm{C}-\mathrm{H}$ amination of allylic and benzylic structural motifs. ${ }^{7}$ However, most of the multistep synthesis required stoichiometric hydride transfer agents and suffered from poor atom economy and copious waste generation. $^{8}$

The development of methodology exigencies the sustainable and greener way of developing the synthetic strategy to valuable commercial feedstocks. The hydrogen borrowing $(\mathrm{BH})$ catalysis, which cascades the dehydrogenation and rehydrogenation processes, adds considerable interest since it is atom efficient and environmentally amicable. ${ }^{9}$ In this context, the anti-Markovnikov functionalizations of allylic alcohols leading to $\gamma$-functionalized alcohols via $\mathrm{BH}$ catalysis have attained enormous attention (Scheme 1b). Williams et al. ${ }^{10}$ and Rodriguez et al. ${ }^{11}$ had independently developed such a reaction using carbon nucleophiles. The anti-Markovnikov hydroamination of allyl alcohols was pioneered by Oe employing a ruthenium catalyst. ${ }^{12}$ Subsequently, Wang et al. reported an alkyl phosphine-based iron catalyst for the anti-Markovnikov amino functionalization of allylic alcohols. ${ }^{13}$ Recently, Xing ${ }^{14}$ and Wang $^{15}$ group independently reported asymmetric hydroamination of arylvinyl alcohols utilizing ruthenium catalysts. While preparing this manuscript, Beller et al. reported alkyl phosphine-based manganese catalyzed formal hydroamination of allyl alcohols using pyrophoric sodium triethylborohydride as catalyst activator. ${ }^{16}$ Although the developed methods are promising, most of them used noble metals as catalysts, external additive as a catalyst activator, and offered limited scope. On the other hand, the modern era of organometallic synthesis demands the development of catalysts based on Earth's abundant transition metals due to easy accessibility, low cost, and less toxicity. ${ }^{17}$ Moreover, the reported protocols used phosphine-based ligands, which are comparatively expensive and prone to undergo degradation under aerial condition such that the beneficial effect of the cheap metal catalysts is often forfeited. Hence, a combination of 3d-transition metal, and a readily available bench-stable ligand, is highly appreciable at present for the anti-Markovnikov hydroamination of allylic alcohols for the synthesis of valuable $\gamma$-amino alcohols.

Recently, we ${ }^{18}$ and others ${ }^{19}$ have established the proficiency of phosphine-free manganese(I) catalysts to carry out wastefree hydrogen transfer reactions. ${ }^{20}$ Manganese is the third most abundant transition metal in the Earth's crust, less toxic, and omnipresent in several biological processes. Not long ago, in addition to protonation/deprotonation metal-ligand bifunctionality, we have exhibited the hemilability of a soft sulfur donor side-arm, which (de)coordinates on-demand, as a crucial design principle for the $\mathrm{Mn}(\mathrm{I})$-catalyzed synthesis of $(\mathrm{n}+1)$ membered cycloalkanes, ${ }^{18 \mathrm{f}} \quad \beta$-branched carbonyl compounds, ${ }^{18 \mathrm{~d}}$ and primary and secondary amines (Scheme 1c). ${ }^{18 \mathrm{~g}}$ Presently, we become interested in developing phosphine-ligand free Mn-catalyst for the anti-Markovnikov hydroamination of allyl alcohols to synthesize valuable $\gamma$-amino alcohols via BH catalysis (Scheme 1d). Notably, the catalyst is 
needed to be highly chemoselective for catalyzing antiMarkovnikov hydroamination reaction, avoiding competing reduction of $\mathrm{C}=\mathrm{X}(\mathrm{X}=\mathrm{C}, \mathrm{N})$ bonds, ${ }^{21}$ allylic substitution, ${ }^{5 \mathrm{~s}, 22}$ and allylic isomerization. ${ }^{23}$

Scheme 1. a) Drug Molecules Prepared from $\gamma$-Amino Alcohols. b) Metal Catalyzed Homogeneous AntiMarkovnikov Hydroamination of Allyl Alcohol.
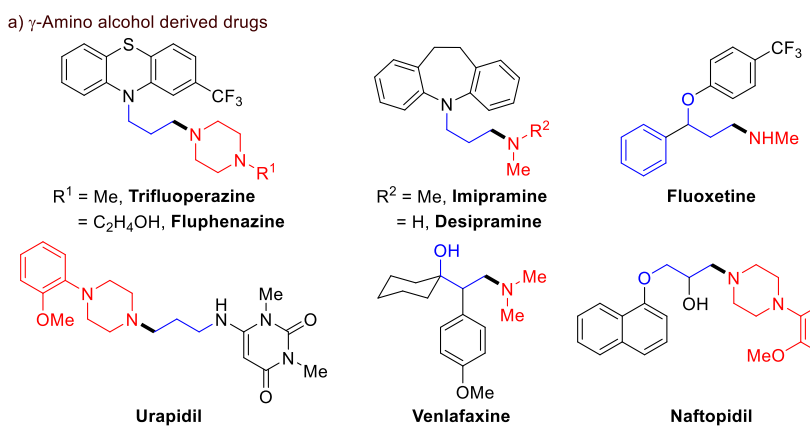

b) Previous anti-Markovnikov hydrofunctionalization of allylic alcohols via hydrogen-borrowing catalysis

$$
\begin{aligned}
& \mathrm{R}_{\mathrm{R}^{2}}^{1} \overbrace{\text { base/additive }}^{\mathrm{OH}}+\mathrm{Nu}-\mathrm{H} \stackrel{\mathrm{M}]}{\stackrel{\mathrm{Ru}}{\mathrm{R}_{\mathrm{R}^{2}}^{1}}} \\
& \begin{aligned}
\mathrm{Nu}-\mathrm{H} & =\mathrm{C}-\mathrm{H},[\mathrm{M}]=\mathrm{Al}, \mathrm{Fe} \\
& =\mathrm{N}-\mathrm{H},[\mathrm{M}]=\mathrm{Ru}, \mathrm{Fe}
\end{aligned}
\end{aligned}
$$

c) Our previous work on manganese catalyzed CC-bond formation and transfer hydrogeneation reactions c) Our previous work on manganese catalyzed CC-bond formation and trans
utilizing phosphine-free manganese catalysts with hemilabile sulfur side-arm

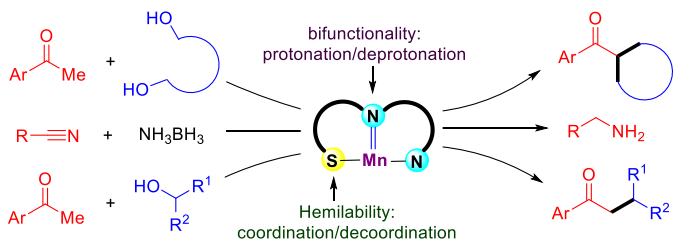

d) This work: Anti-Markovnikov hydroamination of allylic alcohols via hydrogen-borrowing catalysis

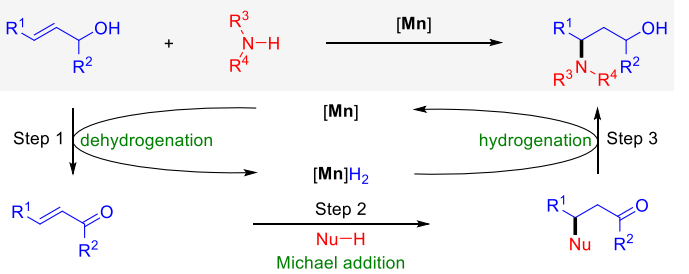

Pursuing this aim, herein, we report a phosphine-free $\mathrm{Mn}(\mathrm{I})$ catalyst Mn1 bearing a soft sulfur donor side-arm in the ligand backbone for the highly regioselective synthesis of $\gamma$-amino alcohols. ${ }^{18 g}$ Encouragingly, the catalyst operated at low loading, tolerated a large variety of amines and allylic alcohol substrates, and can be applied for the diversification of bioactive molecules and for the synthesis of drug molecules. The beneficial role of the soft sulfur donor in the ligand's side-arm has been outlined by equating the activities of Mn1 with its oxygen analog and via control experiments. To the best of our knowledge, phosphine-free base metal complexes for the formal anti-Markovnikov hydroamination of allyl alcohols have not been developed thus far.

Hydroamination of feedstock allyl alcohol (1a) with $\mathrm{N}$ methyl aniline (2a) was chosen as the model reaction (Table 1). Pleasingly, the phosphine-free $\mathrm{Mn}(\mathrm{I})$-catalyst Mn1, having a thiomethoxy side-arm, ${ }^{18 g}$ at a 2 mol\% loading, efficiently catalyze the reaction when the reaction was performed in toluene $(0.25 \mathrm{M})$ at $100{ }^{\circ} \mathrm{C}$ in the presence of a mild base $\mathrm{K}_{2} \mathrm{CO}_{3}$ (entry 1). The desired $\gamma$-amino alcohol product 3aa was obtained in $92 \%$ yield with exclusive anti-Markovnikov selectivity. When the reaction was performed with the $\mathrm{Mn}(\mathrm{I})$-complex
Mn2, having a thiophene side-arm, ${ }^{18 f} 78 \%$ yield of 3aa was noticed (entry 2). On the other hand, more rigid hydrazoneligand derived $\mathrm{Mn}(\mathrm{I})$-complex $\mathbf{M n 3}$, which efficiently catalyzed the $\mathrm{C}$-alkylations of nitriles, ${ }^{18 \mathrm{~b}}$ fail to catalyze the hydroamination reaction (entry 3), indicating the need for the flexible NNS-ligand framework. Among the solvents tested, cyclohexane did not alter the reaction outcome (entry 4). However, polar solvents hampered the reaction (entry 5). The $\mathrm{K}_{2} \mathrm{CO}_{3}$ loading could be reduced to $70 \mathrm{~mol} \%$ without affecting the yield (entry 6). Further reduction gave inferior results (entry 7). Lower yields of the product were also noticed when other bases were used (entry 8). The control experiments demonstrated that the product did not formed in the absence of Mn1 or $\mathrm{K}_{2} \mathrm{CO}_{3}$ (entry 9). Further details of the reaction optimizations are tabulated in Tables S1-S4.

Table 1. Key Reaction Pptimization. ${ }^{a}$

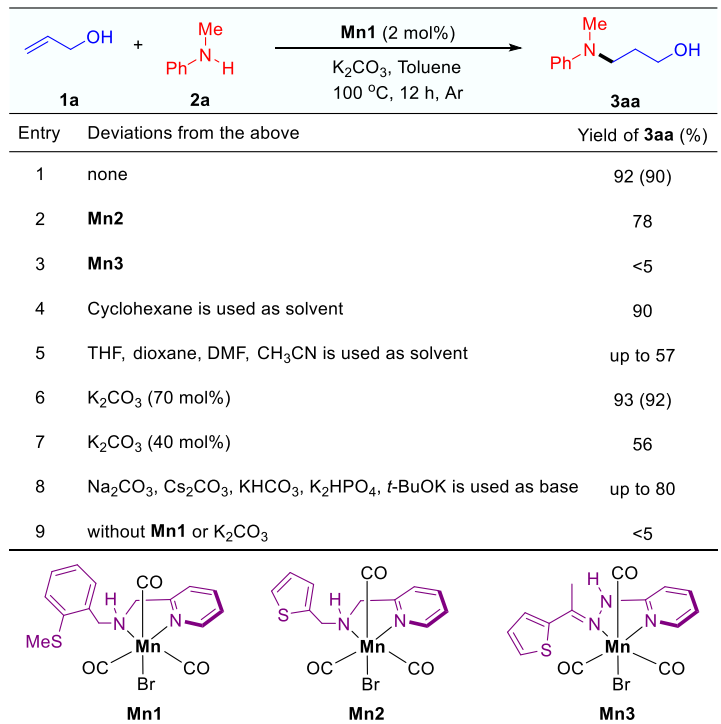

${ }^{a}$ Reaction conditions: 1a $(0.4 \mathrm{mmol}), 2 \mathrm{a}(0.1 \mathrm{mmol}), \mathbf{M n} 1$ (2 $\mathrm{mol} \%), \mathrm{K}_{2} \mathrm{CO}_{3}(0.1 \mathrm{mmol})$, Toluene $(0.25 \mathrm{M}), 100{ }^{\circ} \mathrm{C}, 12 \mathrm{~h}$. Yields were determined by ${ }^{1} \mathrm{H}$ NMR using 1,3,5trimethoxybenzene as internal standard. Isolated yields in the parenthesis.

We then set to explore the scope of the anti-Markovnikov hydroamination reaction (Table 2). We were pleased to find that a vast range of aromatic (2a-s), and aliphatic amines (2tzg) underwent smooth hydroamination reaction with both primary (1a-e) and secondary allylic alcohols (1f-o) while tolerating several functional groups. Notably, in all cases, the $\gamma$ amino alcohols 3 were isolated in exclusive selectivities. The $N$-alkyl anilines (2a-f) exhibited higher reactivity over anilines (2g-p) due to their higher nucleophilicity from alkyl substituent presence on nitrogen. The same is also evident from the effect of substituents at the aryl ring of the amine substrates. An electron-donating methoxy group at the $p$-position leads to the $98 \%$ yield of the $\gamma$-amino alcohol 3ab. Moderately electronic biased halogen substituents furnished the products 3ac3ae in moderate to good yields. In comparison, strongly electron-withdrawing trifluoromethyl substituents at the $p$-position displayed poor reactivity and yielded $47 \%$ of 3af. On the other hand, the reaction was not affected by the sterics of the aryl substituents as the alkyl substituents present at the $o-, m-$, and $p$-position of the aniline substrates $\mathbf{2 h}$-k reacted at equal efficiencies. The halogens functionalized anilines $\mathbf{2 m}-\mathbf{p}$ were also 
Table 2. Scope for the manganese catalyzed hydroamination of allyl alcohols 1 with amines $2 .^{a}$

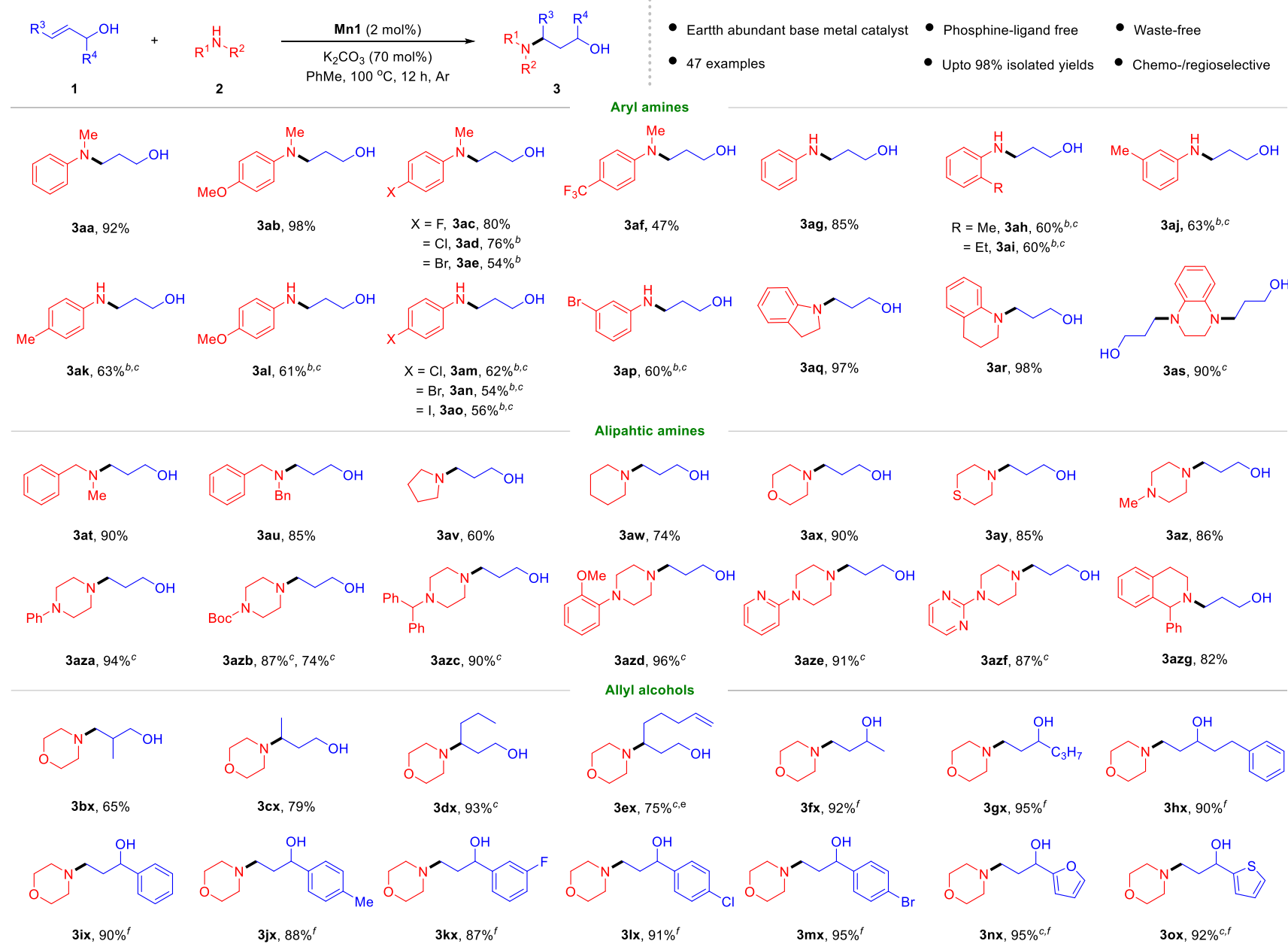

${ }^{a}$ Reaction conditions: 1 (0.25 mmol), 2 (1 mmol), Mn1 (2 mol\%), $\mathrm{K}_{2} \mathrm{CO}_{3}(70 \mathrm{~mol} \%), \mathrm{PhMe}(1 \mathrm{~mL}), 100{ }^{\circ} \mathrm{C}, 12 \mathrm{~h}$. Isolated yields. ${ }^{b} \mathrm{~K}_{2} \mathrm{CO}_{3}(100 \mathrm{~mol} \%) .{ }^{c}$ Reaction time 24 h. ${ }^{d} \mathbf{1 a}(5.37 \mathrm{mmol}, 1 \mathrm{~g}) .{ }^{e} \mathbf{M n 1}(4 \mathrm{~mol} \%), \mathrm{K}_{2} \mathrm{CO}_{3}$ (100 mol\%). ${ }^{f} \mathrm{Toluene}: 2-\mathrm{PrOH}(1: 3)$.

responded equally, furnishing the desired products in moderate yields. Notably, the halogen substituents, including the $p$ iodo group, were completely retained under these mild conditions, thus providing a handle for further derivatizations. Pleasingly, partially reduced heterocyclic arylamines $\mathbf{2 q}, \mathbf{r}$ reacted smoothly under these conditions delivering the products in high $97 \%$ and $98 \%$ yields, respectively. Even double hydroamination of $2 \mathrm{~s}$ could be performed, and the product 3as was isolated in $90 \%$ yield after $24 \mathrm{~h}$.

To further expand the scope of this reaction, a large variety of aliphatic amines were reacted with allyl alcohol. Aliphatic, acyclic amines $(\mathbf{2 t}, \mathbf{u})$, and cyclic amines like pyrrolidine $(\mathbf{2 v})$, piperidine $(\mathbf{2 w})$, morpholine $(\mathbf{2 x})$, and thiomorpholine $(\mathbf{2 y})$ lead to complete conversion to $\gamma$-amino alcohols. However, due to the volatility, the isolated yields for pyrrolidine and piperidine amino alcohol derivatives (3av, 3aw) were found to be moderate. Interestingly the piperazine derivatives $(\mathbf{2 z - z d})$ possessing more than one nitrogen atom, which are important building units in several bioactive molecules, were well-tolerated without decreasing the reaction efficiency as the desired products 3az-3azd were isolated in high $86-96 \%$ yields. The reaction of $\mathbf{2 z b}$ with $\mathbf{1 a}$ could also be performed on a gram scale without significantly affecting the reaction outcome. Piperazines bearing heterocyclic moieties like pyridine (2ze) and pyrimidine (2zf) rings were also tolerated furnishing the desired products in $91 \%$ and $87 \%$ yields, respectively. 1-Phenylisoquinoline (2zg) also underwent a smooth hydroamination reaction delivering the product 3 azg in $82 \%$ yield.

The excellency of the developed methodology induced us to further extend the scope for primary and secondary allyl alcohols. Primary allylic alcohols bearing alkyl substituent at the $\beta$ - (1b) and $\gamma$ - (1d-e) positions furnished the $\gamma$-amino alcohols 3bx-3ex in 65-93\% yields. The homoallylic alcohol, but-3-en-1-ol (1c), underwent exclusive hydroamination at the $\gamma$-position. Notably, a terminal alkene group in the allyl alcohol partner $\mathbf{2 e}$ was retained under these hydrogen transfer conditions.

Secondary allylic alcohols $2 \mathbf{2 f - 0}$ could also be utilized as the coupling partners under the optimized reaction conditions in Table 1 using toluene and 2-propanol (1:3) as the solvent. The latter is used as an additional hydrogen source that allowed the selective formation of $\gamma$-amino alcohol. The alkyl secondary allylic alcohols (1f-h) with different alkyl chains resulted in high $90-95 \%$ yields of the $\gamma$-amino alcohol products. Similarly, the aryl secondary allylic alcohols (1i-m) with different electronic substituents reacted smoothly, and the desired $\gamma$-amino alcohols were isolated in $87-95 \%$ yields. 
Scheme 2. Synthetic Application of Manganese catalyzed Anti-Markovnikov Hydroamination Reaction. (a-c) Diversification of Natural Products and Drug Molecules. (d-g) Synthesis of Drug Molecules. ${ }^{a}$

(a)
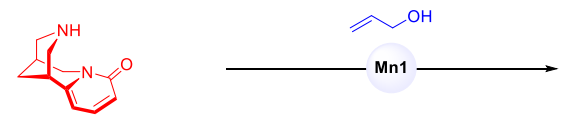

Cytisine, 2zh b)

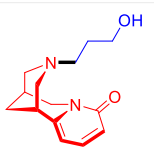

3azh, $88 \%$ (d)

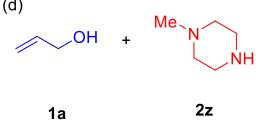

$1 a$

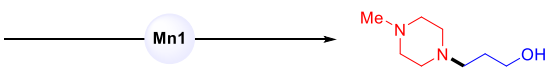

3az, $86 \%$

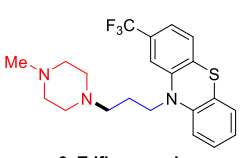
$\mathrm{CHCl}_{3}, 100^{\circ} \mathrm{C}, 6 \mathrm{~h}$

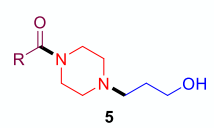

4, Drug or natual product

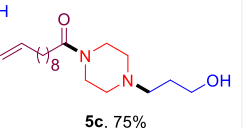

(e) $\mathrm{OH}$

9, Trifluoperazine
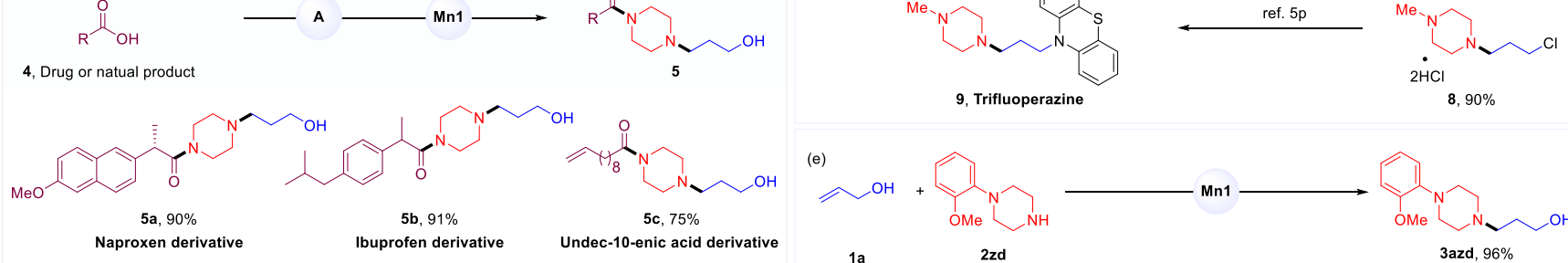

ndec-10-enic acid derivative

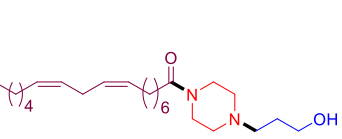

ofen derivative

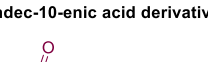

1a
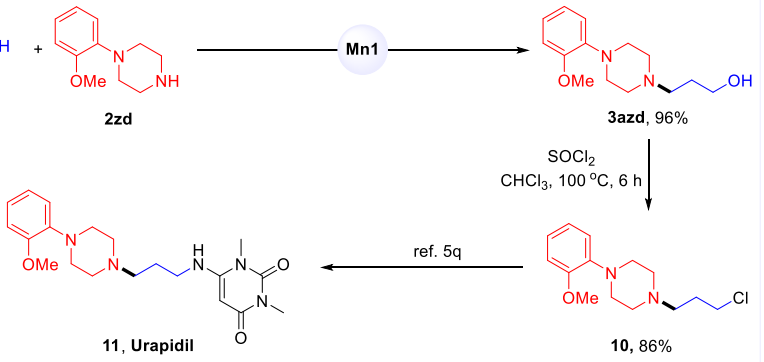

$\mathbf{5 d}, 84 \%$
Linoleic acid derivative
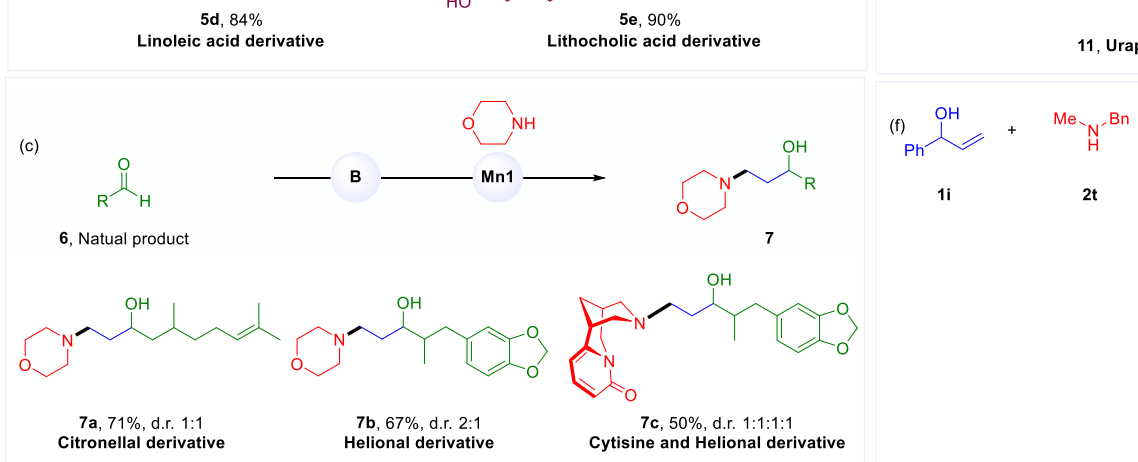

$$
\text { 인 }
$$

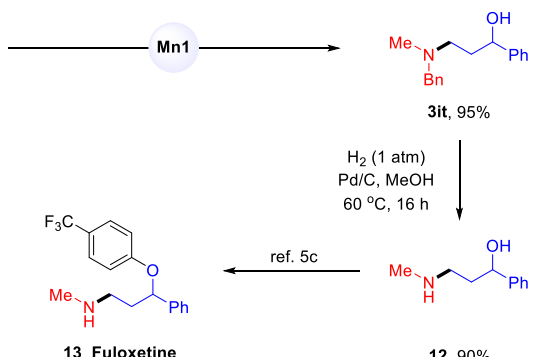

13, Fuloxetine

$12,90 \%$

(g)

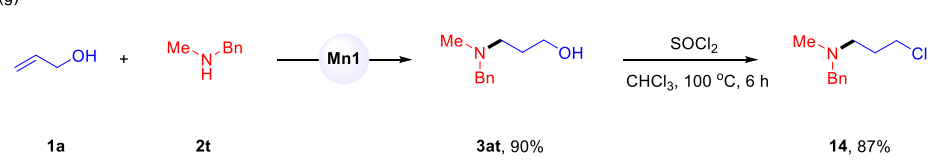

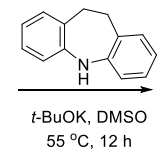

$55^{\circ} \mathrm{C}, 12 \mathrm{~h}$

$14,87 \%$

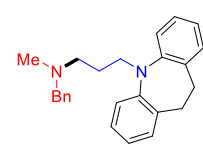

$15,81 \%$

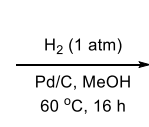

$60^{\circ} \mathrm{C}, 16 \mathrm{~h}$

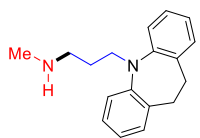

16, Desipramine, $75 \%$

${ }^{a}$ Reaction conditions: A: (i) $N$-Boc piperazine, DMAP, DCC, $\mathrm{CH}_{2} \mathrm{Cl}_{2}$, r.t. (ii) TFA, $\mathrm{CH}_{2} \mathrm{Cl}_{2}$, r.t.; B: Vinyl magnesium bromide, THF, 0 ${ }^{\circ} \mathrm{C}$ to r.t.; Mn1: Table 1, entry 6.

Again, the halogen functional groups were retained under these conditions. Additionally, heteroaromatic furan (2n) and thiophene (2o) containing secondary allylic alcohols were also hydroaminated in excellent $95 \%$ and $92 \%$ yields, respectively.

To further explore the applicability of the $\mathrm{BH}$ methodology, we carried out functionalization of naturally occurring alkaloid, cytisine 2zh that deliver the diversified product 3azh in $88 \%$ isolated yield (Scheme 2a). The derivatives of the anti-inflammatory drugs naproxen $(\mathbf{4 a})^{24}$ and ibuprofen $(\mathbf{4 b}),{ }^{25}$ and the natural products like undec-10-enoic acid (4c), linoleic acid (4d), and lithocholic acid (4e) could efficiently be diversified, furnishing the $\gamma$-amino alcohols 5a-e in $75-91 \%$ yields (Scheme $2 b$ ). Additionally, the allyl alcohols, synthesized from the monoterpenoid citronellal (6a) and the commercially used fragrant helional $(\mathbf{6 b})$, could also be functionalized under the manganese catalyzed hydroamination conditions and the products $7 \mathbf{a}, \mathbf{b}$ were isolated in high yields, and moderate diastereoselectivities (Scheme 2c). Additionally, cytisine $\mathbf{2 z h}$ could be hydroaminated with the allyl alcohol derived from helional (6b), yielding the conjugate $7 \mathrm{c}$ in moderate $50 \%$ yield.

To further demonstrate the synthetic utility of the developed anti-Markovnikov hydroamination reaction, we have synthesized the amino alcohols 3az and 3azd, which could be applied for the formal synthesis of anti-psychotic drug trifluoperazine $(\mathbf{9})^{26}$ and anti-hypertensive drug urapidil (11), ${ }^{27}$ respectively (Scheme $2 \mathrm{~d}, \mathrm{e}$ ). Besides, the precursor 3 it of, the antidepressant drug fluoxetine $(\mathbf{1 3})^{28}$ could also be synthesized in excellent $95 \%$ yield (Scheme 2f). Additionally, to further showcase the synthetic utility of the developed protocol, we have performed the total synthesis of the tricyclic antidepressant desipramine $\mathbf{1 6}^{29}$ (Scheme 2g). Thus, the precursor 3at, synthesized in $90 \%$ yield under the manganese catalysis, was converted to the chloro derivative 14 in $87 \%$ yield. Then after treatment with iminodibenzyl and debenzylation delivered the antidepressant drug molecule desipramine $\mathbf{1 6}$ in $61 \%$ combined yields over two steps. 
Scheme 3. Mechanistic Studies: a) Control Experiments to Probe Bifunctionality and Hemilability of the Ligand Framework, b) Exogenous Ligand Effect, c) Deuterium Labeling Studies, d) Determination of Kinetic Isotope Effect, e) Probing the Formation of $\beta$-Amino Ketone Intermediate, and f) Plausible Reaction Mechanism.
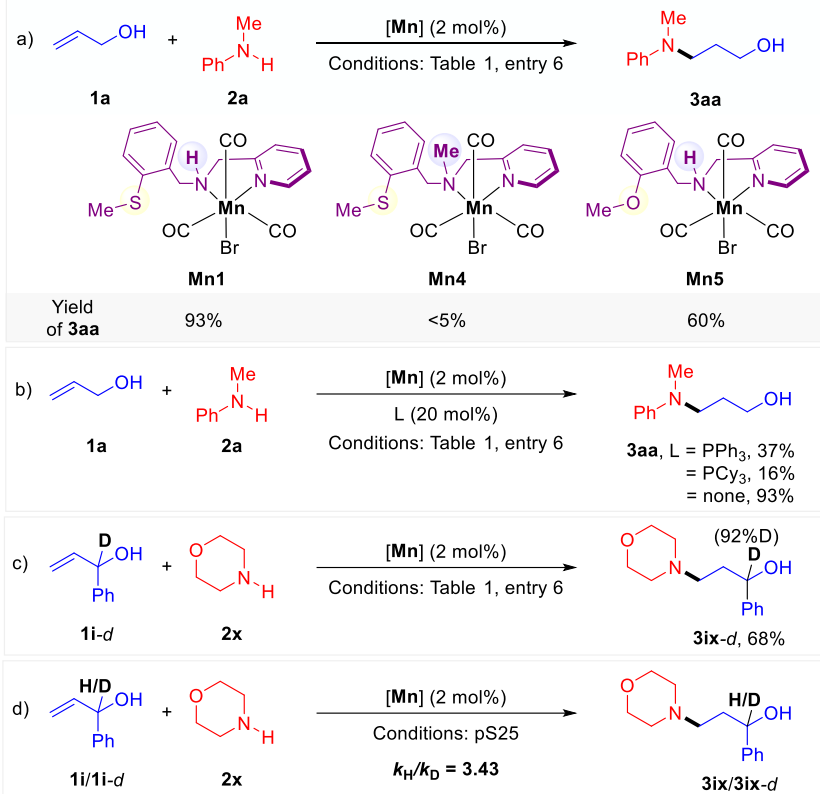

$=\mathrm{PCy}_{3}, 16 \%$
$=$ none, $93 \%$

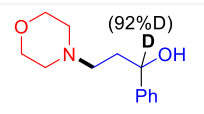

$3 \mathbf{i x}-d, 68 \%$

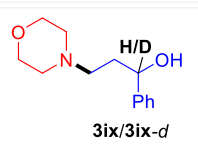

The working hypothesis for the formal anti-Markovnikov hydroamination reaction is outlined in Scheme 1d and Scheme 3. A set of mechanical and kinetic experiments were then performed to probe the $\mathrm{BH}$ catalysis and to delineate the salient feature in the ligand design (Scheme 3). It is anticipated from the concept of metal-ligand bifunctionality that the base-mediated dehydrobromination to ease the alcohol activation will be hampered by substituting the $\mathrm{N}-\mathrm{H}$ proton by N-Me functionality. ${ }^{18 f}$ Supportively, the use of the Mn(I)complex Mn4, having an N-Me group in the ligand backbone, as a catalyst resulted in a trace amount of product formation (Scheme 3a). The beneficial role of the sulfur sidearm in catalyzing the reaction was then probed. We recently set forth the hemilabile co-ordination of sulfur sidearm towards catalyzing the CC-bond formation, ${ }^{18 \mathrm{f}}$ and transfer hydrogenation reactions. ${ }^{18 \mathrm{~g}}$ Along this direction, when the catalysis was performed with Mn5, where the sulfur atom in the ligand backbone is replaced with a weakly polarizable oxygen atom, lacking hemilabile co-ordination to the $\mathrm{Mn}(\mathrm{I})$-center, a lower yield of 3aa was noticed (Scheme 3a). The inhibition by an external strong field ligand, such as triphenylphosphine (37\% yield of 3aa) and tricyclohexylphosphine (16\% yield of 3aa) further supports the hemilabile co-ordination of thiomethoxy sidearm (Scheme 3b).

The deuterium labeling experiment with $\alpha$-deuterated allyl alcohol $1 \mathbf{i}-d$ in toluene resulted in $68 \%$ yield of the corresponding $\gamma$-amino alcohol 3ix- $d$ (Scheme 3c). The $92 \%$ deuterium incorporation at the $\alpha$-position of the alcohol product indicates the occurrence of a $\mathrm{BH}$ cascade in which the deuteration takes place at the carbonyl carbon of $\beta$-amino ketone intermediate by the Mn-D species formed by the dehydrogenation of 1i- $d$. By measuring the yield of 3ix at a different time interval, an initial rate $\left(k_{\mathrm{H}}=1.03 \times 10^{-3} \mathrm{M} / \mathrm{min}\right)$ for the reaction of $\mathbf{1 i}$ with $\mathbf{2 x}$ is determined (see SI for details). The $\alpha$-deuterated allyl alcohol 1i- $d$ reacted slowly $\left(k_{\mathrm{D}}=3.00 \times\right.$ $10^{-4} \mathrm{M} / \mathrm{min}$ ). From the ratio, a primary kinetic isotope effect, KIE $k_{\mathrm{H}} / k_{\mathrm{D}}=3.43$ is obtained, which suggests that the alcohol
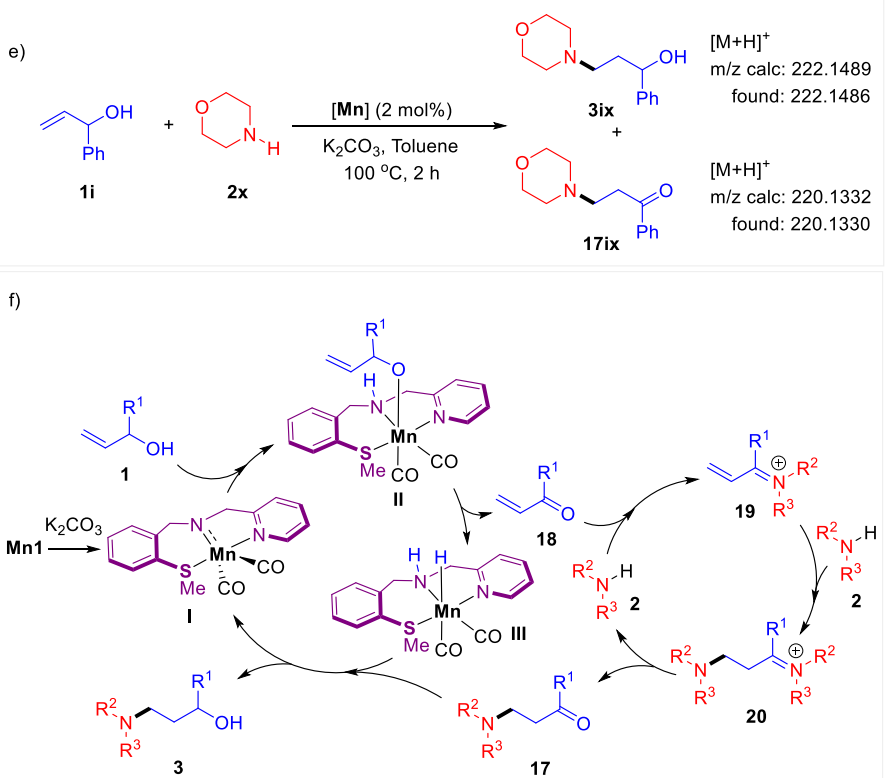

dehydrogenation might be the rate-determining step (Scheme $3 \mathrm{~d})$. The formation of $\beta$-amino ketone intermediate 17ix is also supported by the HRMS analysis of the crude reaction mixture where a $\mathrm{m} / \mathrm{z}$ for $[\mathbf{1 7 i x}+\mathrm{H}]^{+}$is noticed (Scheme $3 \mathrm{e}$ ).

Based on the above experimental findings and previous literature, ${ }^{13-14,18,20}$ a plausible mechanism is proposed (Scheme 3f). The base mediated dehydrobromination of Mn1 generates the amido complex I, which activates allyl alcohol $\mathbf{1}$ to produce the intermediate $\mathbf{I I} .^{18 \mathrm{f}, 18 \mathrm{~g}}$ The hemilabile sulfur arm then facilitates the alcohol dehydrogenation from II in a rate-limiting-step, as supported by the KIE study, to liberate the hydride complex III and the $\alpha, \beta$-unsaturated carbonyl compound 18. The latter condensed with the amine $\mathbf{2}$, generating an iminium ion intermediate 19, which undergoes aza-Michael addition of another amine molecule. The hydrolysis of the formed intermediate 20 liberates the $\beta$ amino ketone 17, which undergoes hydrogenation with III to afford the desired $\gamma$-amino alcohol $\mathbf{3}$ and closes the catalytic cycle.

In conclusion, we have demonstrated an efficient synthesis of $\gamma$-amino alcohols via selective anti-Markovnikov hydroamination of allyl alcohols. The atom-economic reaction was catalyzed by a phosphine-free manganese(I)-complex, and the reaction tolerates various functional groups and heterocyclic moieties. The derivatives of natural products like linoleic acid, lithocholic acid, and citronellal, the drug molecules cytisine, ibuprofen and naproxen, and commercial fragrant helional could be diversified in good to excellent yields. Besides, the reaction could also be performed on a gram scale. The precursors was applied for the formal synthesis of drug molecules trifluoperazine, urapidil, fluoxetine, and for the total synthesis of the antidepressant drug desipramine. The deuterium labeling and the kinetic studies provide evidence about the alcohol oxidation to be the ratedetermining one. The mechanical experiments revealed both M-L bifunctionality and the hemilability of the thiomethoxy 
sidearm to be the salient factors operating to the success of this waste-free hydrogen transfer catalysis.

\section{ASSOCIATED CONTENT}

\section{Supporting Information}

The Supporting Information is available free of charge via the Internet at http://pubs.acs.org.

Experimental procedures, analytical data, kinetic data, NMR spectra of compounds and complexes.

\section{AUTHOR INFORMATION}

\section{Corresponding Author}

* Biplab Maji- Department of Chemical Sciences, Indian Institute of Science Education and Research Kolkata, Mohanpur 741246, India; orcid.org/0000-0001-5034423X; Email: bm@iiserkol.ac.in

\section{Author Contributions}

All authors have given approval to the final version of the manuscript.

Notes

The authors declare no competing financial interest.

\section{ACKNOWLEDGMENT}

The authors acknowledge financial support from DST SERB (grant no. CRG/2019/001232). K. D. and K. S. thank CSIR for SRF.

\section{REFERENCES}

(1) (a) Müller, T. E.; Beller, M., Metal-Initiated Amination of Alkenes and Alkynes. Chem. Rev. 1998, 98, 675-704; (b) Nobis, M.; Drießen-Hölscher, B., Recent Developments in Transition Metal Catalyzed Intermolecular Hydroamination Reactions-A Breakthrough? Angew. Chem. Int. Ed. 2001, 40, 3983-3985; (c) Bytschkov, I.; Doye, S., Group-IV Metal Complexes as Hydroamination Catalysts. Eur. J. Org. Chem. 2003, 2003, 935-946; (d) Patel, M.; Saunthwal, R. K.; Verma, A. K., Base-Mediated Hydroamination of Alkynes. Acc. Chem. Res. 2017, 50, 240-254; (e) Kočovský, P.; Bäckvall, J.-E., The syn/anti-Dichotomy in the Palladium-Catalyzed Addition of Nucleophiles to Alkenes. Chem. Eur. J. 2015, 21, 36-56; (f) McDonald, R. I.; Liu, G.; Stahl, S. S., Palladium(II)-Catalyzed Alkene Functionalization via Nucleopalladation: Stereochemical Pathways and Enantioselective Catalytic Applications. Chem. Rev. 2011, 111, 2981-3019.

(2) (a) Pohlki, F.; Doye, S., The catalytic hydroamination of alkynes. Chem. Soc. Rev. 2003, 32, 104-114; (b) Hong, S.; Marks, T. J., Organolanthanide-Catalyzed Hydroamination. Acc. Chem. Res. 2004, 37, 673-686; (c) Severin, R.; Doye, S., The catalytic hydroamination of alkynes. Chem. Soc. Rev. 2007, 36, 1407-1420; (d) Hesp, K. D., Copper-Catalyzed Regio- and Enantioselective Hydroamination of Alkenes with Hydroxylamines. Angew. Chem. Int. Ed. 2014, 53, 2034-2036; (e) Hultzsch, K. C., Transition MetalCatalyzed Asymmetric Hydroamination of Alkenes (AHA). Adv. Synth. Catal. 2005, 347, 367-391; (f) Pirnot, M. T.; Wang, Y.-M.; Buchwald, S. L., Copper Hydride Catalyzed Hydroamination of Alkenes and Alkynes. Angew. Chem. Int. Ed. 2016, 55, 48-57; (g) Hannedouche, J.; Schulz, E., Hydroamination and Hydroaminoalkylation of Alkenes by Group 3-5 Elements: Recent Developments and Comparison with Late Transition Metals. Organometallics 2018, 37, 4313-4326; (h) Müller, T. E.; Hultzsch, K. C.; Yus, M.; Foubelo, F.; Tada, M., Hydroamination: Direct Addition of Amines to Alkenes and Alkynes. Chem. Rev. 2008, 108 , 3795-3892; (i) Hannedouche, J.; Schulz, E., Asymmetric Hydroamination: A Survey of the Most Recent Developments. Chem. Eur. J. 2013, 19, 4972-4985; (j) Hannedouche, J.; Collin, J.; Trifonov, A.; Schulz, E., Intramolecular enantioselective hydroamination catalyzed by rare earth binaphthylamides. $J$. Organomet. Chem. 2011, 696, 255-262; (k) Bernoud, E.; Lepori, C.; Mellah, M.; Schulz, E.; Hannedouche, J., Recent advances in metal free- and late transition metal-catalysed hydroamination of unactivated alkenes. Catal. Sci. Technol. 2015, 5, 2017-2037; (1) Coman, S. M.; Parvulescu, V. I., Nonprecious Metals Catalyzing Hydroamination and $\mathrm{C}-\mathrm{N}$ Coupling Reactions. Org. Process Res. Dev. 2015, 19, 1327-1355; (m) Huang, L.; Arndt, M.; Gooßen, K.; Heydt, H.; Gooßen, L. J., Late Transition Metal-Catalyzed Hydroamination and Hydroamidation. Chem. Rev. 2015, 115, 25962697; (n) Villa, M.; Jacobi von Wangelin, A., Hydroaminations of Alkenes: A Radical, Revised, and Expanded Version. Angew. Chem. Int. Ed. 2015, 54, 11906-11908; (o) Michon, C.; Abadie, M.-A.; Medina, F.; Agbossou-Niedercorn, F., Recent metal-catalysed asymmetric hydroaminations of alkenes. J. Organomet. Chem. 2017, 847, 13-27.

(3) (a) Seayad, J.; Tillack, A.; Hartung, C. G.; Beller, M., BaseCatalyzed Hydroamination of Olefins: An Environmentally Friendly Route to Amines. Adv. Synth. Catal. 2002, 344, 795-813; (b) Kärkäs, M. D., Photochemical Generation of Nitrogen-Centered Amidyl, Hydrazonyl, and Imidyl Radicals: Methodology Developments and Catalytic Applications. ACS Catal. 2017, 7 , 4999-5022; (c) Beller, M.; Trauthwein, H.; Eichberger, M.; Breindl, C.; Herwig, J.; Müller, T. E.; Thiel, O. R., The First RhodiumCatalyzed Anti-Markovnikov Hydroamination: Studies on Hydroamination and Oxidative Amination of Aromatic Olefins. Chem. Eur. J. 1999, 5, 1306-1319; (d) Utsunomiya, M.; Kuwano, R.; Kawatsura, M.; Hartwig, J. F., Rhodium-Catalyzed AntiMarkovnikov Hydroamination of Vinylarenes. J. Am. Chem. Soc. 2003, 125, 5608-5609; (e) Kemper, J.; Studer, A., Stable Reagents for the Generation of N-Centered Radicals: Hydroamination of Norbornene. Angew. Chem. Int. Ed. 2005, 44, 4914-4917; (f) Leitch, D. C.; Payne, P. R.; Dunbar, C. R.; Schafer, L. L., Broadening the Scope of Group 4 Hydroamination Catalysis Using a Tethered Ureate Ligand. J. Am. Chem. Soc. 2009, 131, 18246-18247; (g) Rucker, R. P.; Whittaker, A. M.; Dang, H.; Lalic, G., Synthesis of Tertiary Alkyl Amines from Terminal Alkenes: Copper-Catalyzed Amination of Alkyl Boranes. J. Am. Chem. Soc. 2012, 134, 65716574; (h) Zhu, S.; Niljianskul, N.; Buchwald, S. L., Enantio- and Regioselective CuH-Catalyzed Hydroamination of Alkenes. J. Am. Chem. Soc. 2013, 135, 15746-15749; (i) Nguyen, T. M.; Nicewicz, D. A., Anti-Markovnikov Hydroamination of Alkenes Catalyzed by an Organic Photoredox System. J. Am. Chem. Soc. 2013, 135, 95889591; (j) Strom, A. E.; Hartwig, J. F., One-Pot Anti-Markovnikov Hydroamination of Unactivated Alkenes by Hydrozirconation and Amination. J. Org. Chem. 2013, 78, 8909-8914; (k) Zhu, S.; Buchwald, S. L., Enantioselective CuH-Catalyzed AntiMarkovnikov Hydroamination of 1,1-Disubstituted Alkenes. J. Am. Chem. Soc. 2014, 136, 15913-15916; (1) Nguyen, T. M.; Manohar, N.; Nicewicz, D. A., anti-Markovnikov Hydroamination of Alkenes Catalyzed by a Two-Component Organic Photoredox System: Direct Access to Phenethylamine Derivatives. Angew. Chem. Int. Ed. 2014, 53, 6198-6201; (m) Bronner, S. M.; Grubbs, R. H., Formal anti-Markovnikov hydroamination of terminal olefins. Chem. Sci. 2014, 5, 101-106; (n) Ensign, S. C.; Vanable, E. P.; Kortman, G. D.; Weir, L. J.; Hull, K. L., Anti-Markovnikov Hydroamination of Homoallylic Amines. J. Am. Chem. Soc. 2015, 137, 13748-13751; (o) Yu, Y.-F.; Shu, C.; Zhou, B.; Li, J.-Q.; Zhou, J.-M.; Ye, L.-W., Efficient and practical synthesis of enantioenriched 2,3-dihydropyrroles through gold-catalyzed antiMarkovnikov hydroamination of chiral homopropargyl sulfonamides. Chem. Commun. 2015, 51, 2126-2129; (p) Kim, K. E.; Li, J.; Grubbs, R. H.; Stoltz, B. M., Catalytic Anti-Markovnikov Transformations of Hindered Terminal Alkenes Enabled by Aldehyde-Selective Wacker-Type Oxidation. J. Am. Chem. Soc. 2016, 138, 13179-13182; (q) Yang, X.-H.; Lu, A.; Dong, V. M., Intermolecular Hydroamination of 1,3-Dienes To Generate Homoallylic Amines. J. Am. Chem. Soc. 2017, 139, 14049-14052; (r) Kohler, D. G.; Gockel, S. N.; Kennemur, J. L.; Waller, P. J.; Hull, K. L., Palladium-catalysed anti-Markovnikov selective oxidative amination. Nat. Chem. 2018, 10, 333-340; (s) Thomas, A. 
A.; Speck, K.; Kevlishvili, I.; Lu, Z.; Liu, P.; Buchwald, S. L., Mechanistically Guided Design of Ligands That Significantly Improve the Efficiency of $\mathrm{CuH}$-Catalyzed Hydroamination Reactions. J. Am. Chem. Soc. 2018, 140, 13976-13984; (t) Zhu, Q.; Graff, D. E.; Knowles, R. R., Intermolecular Anti-Markovnikov Hydroamination of Unactivated Alkenes with Sulfonamides Enabled by Proton-Coupled Electron Transfer. J. Am. Chem. Soc. 2018, 140, 741-747; (u) Lardy, S. W.; Schmidt, V. A., Intermolecular Radical Mediated Anti-Markovnikov Alkene Hydroamination Using N-Hydroxyphthalimide. J. Am. Chem. Soc. 2018, 140, 12318-12322; (v) Miller, D. C.; Ganley, J. M.; Musacchio, A. J.; Sherwood, T. C.; Ewing, W. R.; Knowles, R. R., Anti-Markovnikov Hydroamination of Unactivated Alkenes with Primary Alkyl Amines. J. Am. Chem. Soc. 2019, 141, 16590-16594; (w) Park, S.; Jeong, J.; Fujita, K.-i.; Yamamoto, A.; Yoshida, H., Anti-Markovnikov Hydroamination of Alkenes with Aqueous Ammonia by Metal-Loaded Titanium Oxide Photocatalyst. J. Am. Chem. Soc. 2020, 142, 12708-12714; (x) Ye, Z.-P.; Hu, Y.-Z.; Xia, P.-J.; Xiang, H.-Y.; Chen, K.; Yang, H., Photocatalytic intermolecular anti-Markovnikov hydroamination of unactivated alkenes with N-hydroxyphthalimide. Org. Chem. Front 2021, 8, 273-277.

(4) (a) Yang, Y.; Shi, S.-L.; Niu, D.; Liu, P.; Buchwald, S. L., Catalytic asymmetric hydroamination of unactivated internal olefins to aliphatic amines. Science 2015, 349, 62; (b) Shi, S.-L.; Wong, Z. L.; Buchwald, S. L., Copper-catalysed enantioselective stereodivergent synthesis of amino alcohols. Nature 2016, 532, 353356; (c) Ichikawa, S.; Buchwald, S. L., Asymmetric Synthesis of $\gamma$ Amino Alcohols by Copper-Catalyzed Hydroamination. Org. Lett. 2019, 21, 8736-8739; (d) Liu, R. Y.; Buchwald, S. L., CuHCatalyzed Olefin Functionalization: From Hydroamination to Carbonyl Addition. Acc. Chem. Res. 2020, 53, 1229-1243.

(5) (a) Wang, Y. F.; Izawa, T.; Kobayashi, S.; Ohno, M., Stereocontrolled synthesis of (+)-negamycin from an acyclic homoallylamine by 1,3 -asymmetric induction. J. Am. Chem. Soc. 1982, 104, 6465-6466; (b) Benz, G.; Henning, R.; Stasch, J.-P., 1,3Dipolar Cycloaddition as the Key Reaction in the Synthesis of Potent Renin Inhibitors. Angew. Chem. Int. Ed. 1991, 30, 17021704; (c) Sakuraba, S.; Achiwa, K., Efficient Asymmetric Hydrogenation of \&beta;- and \&gamma;-Amino Ketone Derivatives Leading to Practical Synthesis of Fluoxetine and Eprozinol. Chem. Pharm. Bull. 1995, 43, 748-753; (d) Boyd, S. A.; Fung, A. K. L.; Baker, W. R.; Mantei, R. A.; Armiger, Y. L.; Stein, H. H.; Cohen, J.; Egan, D. A.; Barlow, J. L., C-Terminal modifications of nonpeptide renin inhibitors: improved oral bioavailability via modification of physicochemical properties. J. Med. Chem. 1992, 35, 1735-1746; (e) Carlier, P. R.; Lo, M. M. C.; Lo, P. C. K.; Richelson, E.; Tatsumi, M.; Reynolds, I. J.; Sharma, T. A., Synthesis of a potent wide-spectrum serotonin-, norepinephrine-, dopamine-reuptake inhibitor (SNDRI) and a species-selective dopamine-reuptake inhibitor based on the gamma-amino alcohol functional group. Bioorg. Med. Chem. Lett. 1998, 8, 487-492; (f) Kempf, D. J.; Sham, H. L.; Marsh, K. C.; Flentge, C. A.; Betebenner, D.; Green, B. E.; McDonald, E.; Vasavanonda, S.; Saldivar, A.; Wideburg, N. E.; Kati, W. M.; Ruiz, L.; Zhao, C.; Fino, L.; Patterson, J.; Molla, A.; Plattner, J. J.; Norbeck, D. W., Discovery of Ritonavir, a Potent Inhibitor of HIV Protease with High Oral Bioavailability and Clinical Efficacy. J. Med. Chem. 1998, 41, 602-617; (g) Benedetti, F.; Norbedo, S., Epoxyalcohol route to hydroxyethylene dipeptide isosteres: a new synthesis of the diaminoalcohol core of HIV-protease inhibitor ABT-538 (Ritonavir). Chem. Commun. 2001, 203-204; (h) Yasuda, S.; Kitagawa, H.; Ueno, M.; Ishitani, H.; Fukasawa, M.; Nishijima, M.; Kobayashi, S.; Hanada, K., A Novel Inhibitor of Ceramide Trafficking from the Endoplasmic Reticulum to the Site of Sphingomyelin Synthesis*. J. Biol. Chem. 2001, 276, 43994-44002; (i) Sham, H. L.; Zhao, C.; Li, L.; Betebenner, D. A.; Saldivar, A.; Vasavanonda, S.; Kempf, D. J.; Plattner, J. J.; Norbeck, D. W., Novel lopinavir analogues incorporating non-Aromatic P-1 side chains-Synthesis and structure-Activity relationships. Bioorg. Med. Chem. Lett. 2002, 12, 3101-3103; (j) Steinmetz, H.; Glaser,
N.; Herdtweck, E.; Sasse, F.; Reichenbach, H.; Höfle, G., Isolation, Crystal and Solution Structure Determination, and Biosynthesis of Tubulysins-Powerful Inhibitors of Tubulin Polymerization from Myxobacteria. Angew. Chem. Int. Ed. 2004, 43, 4888-4892; (k) Kakei, H.; Nemoto, T.; Ohshima, T.; Shibasaki, M., Efficient Synthesis of Chiral $\alpha$ - and $\beta$-Hydroxy Amides: Application to the Synthesis of (R)-Fluoxetine. Angew. Chem. Int. Ed. 2004, 43, 317 320; (1) Fujima, Y.; Ikunaka, M.; Inoue, T.; Matsumoto, J., Synthesis of (S)-3-(N-Methylamino)-1-(2-thienyl)propan-1-ol: Revisiting Eli Lilly's Resolution-Racemization-Recycle Synthesis of Duloxetine for Its Robust Processes. Org. Process Res. Dev 2006, 10, 905-913; (m) Lait, S. M.; Rankic, D. A.; Keay, B. A., 1,3Aminoalcohols and Their Derivatives in Asymmetric Organic Synthesis. Chem. Rev. 2007, 107, 767-796; (n) Traff, A.; Lihammar, R.; Backvall, J. E., A chemoenzymatic dynamic kinetic resolution approach to enantiomerically pure (R)- and (S)-duloxetine. J. Org. Chem. 2011, 76, 3917-21; (o) Li, W.; Zhang, W.; Ma, X.; Wang, P.; $\mathrm{Du}, \mathrm{M}$., New and efficient technique for the synthesis of Urapidil using $\beta$-cyclodextrin as an inverse phase-transfer catalyst. Appl. Catal., A 2012, 419-420, 210-214; (p) Ni, M. Process for preparation method of trifluoperazine hydrochloride. CN102690245A, 2012; (q) Gharpure, M.; Rane, D.; Shukla, M. C.; Patil, P. V.; Patle, G. T.; Lad, S. M.; Baviskar, D. B. Process for preparation of urapidil. IN2011MU01217A, 2012; (r) Zhou, J. N.; Fang, Q.; Hu, Y. H.; Yang, L. Y.; Wu, F. F.; Xie, L. J.; Wu, J.; Li, S., Copper(II)-catalyzed enantioselective hydrosilylation of halosubstituted alkyl aryl and heteroaryl ketones: asymmetric synthesis of (R)-fluoxetine and (S)-duloxetine. Org. Biomol. Chem. 2014, 12, 1009-17; (s) Emayavaramban, B.; Roy, M.; Sundararaju, B., IronCatalyzed Allylic Amination Directly from Allylic Alcohols. Chem. Eur. J. 2016, 22, 3952-3955.

(6) (a) Barluenga, J.; Aguilar, E.; Fustero, S.; Olano, B.; Viado, A. L., Stereoselective synthesis of 1,3-amino alcohols and 1,3amino ketones. J. Org. Chem. 1992, 57, 1219-1223; (b) Haight, A. R.; Stuk, T. L.; Allen, M. S.; Bhagavatula, L.; Fitzgerald, M.; Hannick, S. M.; Kerdesky, F. A. J.; Menzia, J. A.; Parekh, S. I.; Robbins, T. A.; Scarpetti, D.; Tien, J.-H. J., Reduction of an Enaminone: Synthesis of the Diamino Alcohol Core of Ritonavir. Org. Process Res. Dev 1999, 3, 94-100; (c) Keck, G. E.; Truong, A. P., Directed Reduction of $\beta$-Amino Ketones to Syn or Anti 1,3Amino Alcohol Derivatives. Org. Lett. 2002, 4, 3131-3134; (d) Bartoli, G.; Bartolacci, M.; Giuliani, A.; Marcantoni, E.; Massaccesi, M.; Torregiani, E., Improved Heteroatom Nucleophilic Addition to Electron-Poor Alkenes Promoted by $\mathrm{CeCl} 3 \cdot 7 \mathrm{H} 2 \mathrm{O} / \mathrm{NaI}$ System Supported on Alumina in Solvent-Free Conditions. J. Org. Chem. 2005, 70, 169-174; (e) Aschwanden, P.; Kværnø, L.; Geisser, R. W.; Kleinbeck, F.; Carreira, E. M., Reduction of 2,3Dihydroisoxazoles to $\beta$-Amino Ketones and $\beta$-Amino Alcohols. Org. Lett. 2005, 7, 5741-5742; (f) Liu, D.; Gao, W.; Wang, C.; Zhang, X., Practical Synthesis of Enantiopure $\gamma$-Amino Alcohols by Rhodium-Catalyzed Asymmetric Hydrogenation of $\beta$-SecondaryAmino Ketones. Angew. Chem. Int. Ed. 2005, 44, 1687-1689; (g) Fustero, S.; Jiménez, D.; Moscardó, J.; Catalán, S.; del Pozo, C., Enantioselective Organocatalytic Intramolecular Aza-Michael Reaction: a Concise Synthesis of (+)-Sedamine, (+)-Allosedamine, and (+)-Coniine. Org. Lett. 2007, 9, 5283-5286; (h) Geng, H.; Zhang, W.; Chen, J.; Hou, G.; Zhou, L.; Zou, Y.; Wu, W.; Zhang, $\mathrm{X}$., Rhodium-Catalyzed Enantioselective and Diastereoselective Hydrogenation of $\beta$-Ketoenamides: Efficient Access to anti 1,3Amino Alcohols. Angew. Chem. Int. Ed. 2009, 48, 6052-6054; (i) Millet, R.; Träff, A. M.; Petrus, M. L.; Bäckvall, J.-E., Enantioselective Synthesis of syn- and anti-1,3-Aminoalcohols via $\beta$-Aminoketones and Subsequent Reduction/Dynamic Kinetic Asymmetric Transformation. J. Am. Chem. Soc. 2010, 132, 1518215184; (j) Geng, H.; Zhang, X.; Chang, M.; Zhou, L.; Wu, W.; Zhang, X., Ruthenium-Catalyzed Asymmetric Hydrogenation of $\beta$ Keto- enamines: An Efficient Approach to Chiral $\gamma$-Amino Alcohols. Adv. Synth. Catal. 2011, 353, 3039-3043; (k) Calow, A. D. J.; Batsanov, A. S.; Pujol, A.; Solé, C.; Fernández, E.; Whiting, A., A Selective Transformation of Enals into Chiral $\gamma$-Amino Alcohols. Org. Lett. 2013, 15, 4810-4813; (1) Wang, J.; Liu, D.; Liu, 
Y.; Zhang, W., Asymmetric hydrogenation of $\beta$-amino ketones with the bimetallic complex RuPHOX-Ru as the chiral catalyst. Org. Biomol. Chem. 2013, 11, 3855-3861; (m) Verkade, J. M. M.; Quaedflieg, P. J. L. M.; Verzijl, G. K. M.; Lefort, L.; van Delft, F. L.; de Vries, J. G.; Rutjes, F. P. J. T., Enantio- and diastereoselective synthesis of $\gamma$-amino alcohols. Chem. Commun. 2015, 51, 14462-14464; (n) Hu, Q.; Zhang, Z.; Liu, Y.; Imamoto, T.; Zhang, W., ZnCl2-Promoted Asymmetric Hydrogenation of $\beta$ Secondary-Amino Ketones Catalyzed by a P-Chiral RhBisphosphine Complex. Angew. Chem. Int. Ed. 2015, 54, 22602264; (o) Wang, J.; Wang, Y.; Liu, D.; Zhang, W., Asymmetric Hydrogenation of $\beta$-Secondary Amino Ketones Catalyzed by a Ruthenocenyl Phosphino-oxazoline-ruthenium Complex (RuPHOX$\mathrm{Ru})$ : the Synthesis of $\gamma$-Secondary Amino Alcohols. Adv. Synth. Catal. 2015, 357, 3262-3272; (p) Wu, L.; Jin, R.; Li, L.; Hu, X.; Cheng, T.; Liu, G., A Michael Addition-Asymmetric Transfer Hydrogenation One-Pot Enantioselective Tandem Process for Syntheses of Chiral $\gamma$-Secondary Amino Alcohols. Org. Lett. 2017, 19, 3047-3050; (q) Zhang, Y.-Q.; Bohle, F.; Bleith, R.; Schnakenburg, G.; Grimme, S.; Gansäuer, A., Synthesis of 1,3Amino Alcohols by Hydroxy-Directed Aziridination and Aziridine Hydrosilylation. Angew. Chem. Int. Ed. 2018, 57, 13528-13532.

(7) (a) Milczek, E.; Boudet, N.; Blakey, S., Enantioselective C-H Amination Using Cationic Ruthenium(II)-pybox Catalysts. Angew. Chem. Int. Ed. 2008, 47, 6825-6828; (b) Rice, G. T.; White, M. C., Allylic $\mathrm{C}-\mathrm{H}$ Amination for the Preparation of syn-1,3-Amino Alcohol Motifs. J. Am. Chem. Soc. 2009, 131, 11707-11711; (c) Lee, J. S.; Kim, D.; Lozano, L.; Kong, S. B.; Han, H., Concise Asymmetric Synthesis of Orthogonally Protected syn- and anti-1,3Aminoalcohols. Org. Lett. 2013, 15, 554-557.

(8) Gao, Y.; Sharpless, K. B., Asymmetric synthesis of both enantiomers of tomoxetine and fluoxetine. Selective reduction of 2,3-epoxycinnamyl alcohol with Red-Al. J. Org. Chem. 1988, 53, 4081-4084.

(9) (a) Guillena, G.; Ramón, D. J.; Yus, M., Hydrogen Autotransfer in the N-Alkylation of Amines and Related Compounds using Alcohols and Amines as Electrophiles. Chem. Rev. 2010, 110, 1611-1641; (b) Gunanathan, C.; Milstein, D., Applications of Acceptorless Dehydrogenation and Related Transformations in Chemical Synthesis. Science 2013, 341, 1229712; (c) Schranck, J.; Tlili, A.; Beller, M., More Sustainable Formation of C-N and C-C Bonds for the Synthesis of NHeterocycles. Angew. Chem. Int. Ed. 2013, 52, 7642-7644; (d) Obora, Y., Recent Advances in $\alpha$-Alkylation Reactions using Alcohols with Hydrogen Borrowing Methodologies. ACS Catal. 2014, 4, 3972-3981; (e) Yang, Q.; Wang, Q.; Yu, Z., Substitution of alcohols by $\mathrm{N}$-nucleophiles via transition metal-catalyzed dehydrogenation. Chem. Soc. Rev. 2015, 44, 2305-2329; (f) Corma, A.; Navas, J.; Sabater, M. J., Advances in One-Pot Synthesis through Borrowing Hydrogen Catalysis. Chem. Rev. 2018, 118, 1410-1459.

(10) (a) Black, P. J.; Harris, W.; Williams, J. M. J., Catalytic Electronic Activation: Indirect Addition of Nucleophiles to an Allylic Alcohol. Angew. Chem. Int. Ed. 2001, 40, 4475-4476; (b) Black, P. J.; Edwards, M. G.; Williams, J. M. J., Catalytic electronic activation as a tool for the addition of stabilised nucleophiles to allylic alcohols. Tetrahedron 2005, 61, 1363-1374.

(11) (a) Quintard, A.; Constantieux, T.; Rodriguez, J., An iron/amine-catalyzed cascade process for the enantioselective functionalization of allylic alcohols. Angew. Chem. Int. Ed. 2013, 52, 12883-7; (b) Roudier, M.; Constantieux, T.; Quintard, A.; Rodriguez, J., Triple Iron/Copper/Iminium Activation for the Efficient Redox Neutral Catalytic Enantioselective Functionalization of Allylic Alcohols. ACS Catal. 2016, 6, 52365244.

(12) Nakamura, Y.; Ohta, T.; Oe, Y., A formal anti-Markovnikov hydroamination of allylic alcohols via tandem oxidation/1,4conjugate addition/1,2-reduction using a $\mathrm{Ru}$ catalyst. Chem. Commun. 2015, 51, 7459-62.

(13) Ma, W.; Zhang, X.; Fan, J.; Liu, Y.; Tang, W.; Xue, D.; Li, C.; Xiao, J.; Wang, C., Iron-Catalyzed Anti-Markovnikov
Hydroamination and Hydroamidation of Allylic Alcohols. J. Am. Chem. Soc. 2019, 141, 13506-13515.

(14) Pan, Y.; You, Y.; He, D.; Chen, F.; Chang, X.; Jin, M. Y.; Xing, X., Asymmetric Synthesis of $\gamma$-Secondary Amino Alcohols via a Borrowing-Hydrogen Cascade. Org. Lett. 2020, 22, 72787283.

(15) Xu, R.; Wang, K.; Liu, H.; Tang, W.; Sun, H.; Xue, D.; Xiao, J.; Wang, C., Anti-Markovnikov Hydroamination of Racemic Allylic Alcohols to Access Chiral $\gamma$-Amino Alcohols. Angew. Chem. Int. Ed. 2020, 59, 21959-21964.

(16) Duarte, L.; Bourriquen, F.; Junge, K.; Beller, M., Catalytic Formal Hydroamination of Allylic Alcohols using Manganese PNPPincer Complexes. Adv. Synth. Catal. 2021, doi: 10.1002/adsc.202100081.

(17) Bullock, R. M., Catalysis without Precious Metals. WileyVCH: Weinheim, 2010.

(18) (a) Barman, M. K.; Waiba, S.; Maji, B., ManganeseCatalyzed Direct Olefination of Methyl-Substituted Heteroarenes with Primary Alcohols. Angew. Chem. Int. Ed. 2018, 57, 91269130; (b) Jana, A.; Reddy, C. B.; Maji, B., Manganese Catalyzed $\alpha$ Alkylation of Nitriles with Primary Alcohols. ACS Catal. 2018, 8, 9226-9231; (c) Barman, M. K.; Jana, A.; Maji, B., Phosphine-Free NNN-Manganese Complex Catalyzed $\alpha$-Alkylation of Ketones with Primary Alcohols and Friedländer Quinoline Synthesis. Adv. Synth. Catal. 2018, 360, 3233-3238; (d) Waiba, S.; Jana, S. K.; Jati, A.; Jana, A.; Maji, B., Manganese complex-catalysed $\alpha$-alkylation of ketones with secondary alcohols enables the synthesis of $\beta$-branched carbonyl compounds. Chem. Commun. 2020, 56, 8376-8379; (e) Das, K.; Kumar, A.; Jana, A.; Maji, B., Synthesis and characterization of $\mathrm{N}, \mathrm{N}$-chelate manganese complexes and applications in $\mathrm{CN}$ coupling reactions. Inorg. Chim. Acta 2020, 502, 119358; (f) Jana, A.; Das, K.; Kundu, A.; Thorve, P. R.; Adhikari, D.; Maji, B., A Phosphine-Free Manganese Catalyst Enables Stereoselective Synthesis of $(1+n)$-Membered Cycloalkanes from Methyl Ketones and 1,n-Diols. ACS Catal. 2020, 10, 2615-2626; (g) Sarkar, K.; Das, K.; Kundu, A.; Adhikari, D.; Maji, B., PhosphineFree Manganese Catalyst Enables Selective Transfer Hydrogenation of Nitriles to Primary and Secondary Amines Using AmmoniaBorane. ACS Catal. 2021, 11, 2786-2794.

(19) (a) Bruneau-Voisine, A.; Wang, D.; Dorcet, V.; Roisnel, T.; Darcel, C.; Sortais, J.-B., Transfer Hydrogenation of Carbonyl Derivatives Catalyzed by an Inexpensive Phosphine-Free Manganese Precatalyst. Org. Lett. 2017, 19, 3656-3659; (b) Liu, T.; Wang, L.; Wu, K.; Yu, Z., Manganese-Catalyzed $\beta$-Alkylation of Secondary Alcohols with Primary Alcohols under Phosphine-Free Conditions. ACS Catal. 2018, 8, 7201-7207; (c) Das, K.; Mondal, A.; Pal, D.; Srimani, D., Sustainable Synthesis of Quinazoline and 2-Aminoquinoline via Dehydrogenative Coupling of 2Aminobenzyl Alcohol and Nitrile Catalyzed by Phosphine-Free Manganese Pincer Complex. Org. Lett. 2019, 21, 3223-3227; (d) Mondal, A.; Sahoo, M. K.; Subaramanian, M.; Balaraman, E., Manganese(I)-Catalyzed Sustainable Synthesis of Quinoxaline and Quinazoline Derivatives with the Liberation of Dihydrogen. J. Org. Chem. 2020, 85, 7181-7191; (e) Vasilenko, V.; Blasius, C. K.; Wadepohl, H.; Gade, L. H., Mechanism-Based Enantiodivergence in Manganese Reduction Catalysis: A Chiral Pincer Complex for the Highly Enantioselective Hydroboration of Ketones. Angew. Chem. Int. Ed. 2017, 56, 8393-8397; (f) van Putten, R.; Benschop, J.; de Munck, V. J.; Weber, M.; Muller, C.; Filonenko, G. A.; Pidko, E. A., Efficient and Practical Transfer Hydrogenation of Ketones Catalyzed by a Simple Bidentate Mn-NHC Complex. ChemCatChem 2019, 11, 5232-5235; (g) Huang, M.; Li, Y.; Li, Y.; Liu, J.; Shu, S.; Liu, Y.; Ke, Z., Room temperature N-heterocyclic carbene manganese catalyzed selective $\mathrm{N}$-alkylation of anilines with alcohols. Chem. Commun. 2019, 55, 6213-6216; (h) Papa, V.; Cao, Y.; Spannenberg, A.; Junge, K.; Beller, M., Development of a practical non-noble metal catalyst for hydrogenation of $\mathrm{N}$ heteroarenes. Nat. Catal. 2020, 3, 135-142; (i) Fu, S.; Shao, Z.; Wang, Y.; Liu, Q., Manganese-Catalyzed Upgrading of Ethanol into 1-Butanol. J. Am. Chem. Soc. 2017, 139, 11941-11948; (j) Wang, Y.; Shao, Z.; Zhang, K.; Liu, Q., Manganese-Catalyzed Dual- 
Deoxygenative Coupling of Primary Alcohols with 2-Arylethanols. Angew. Chem. Int. Ed. 2018, 57, 15143-15147.

(20) (a) Maji, B.; Barman, M. K., Recent Developments of Manganese Complexes for Catalytic Hydrogenation and Dehydrogenation Reactions. Synthesis 2017, 49, 3377-3393; (b) Garbe, M.; Junge, K.; Beller, M., Homogeneous Catalysis by Manganese-Based Pincer Complexes. Eur. J. Org. Chem. 2017, 2017, 4344-4362; (c) Valyaev, D. A.; Lavigne, G.; Lugan, N., Manganese organometallic compounds in homogeneous catalysis: Past, present, and prospects. Coord. Chem. Rev. 2016, 308, 191235; (d) Hu, Y.; Wang, C., Manganese-Catalyzed C-H Olefination Reactions. ChemCatChem 2019, 11, 1167-1174; (e) Mukherjee, A.; Milstein, D., Homogeneous Catalysis by Cobalt and Manganese Pincer Complexes. ACS Catal. 2018, 8, 11435-11469; (f) Irrgang, T.; Kempe, R., 3d-Metal Catalyzed N- and C-Alkylation Reactions via Borrowing Hydrogen or Hydrogen Autotransfer. Chem. Rev. 2019, 119, 2524-2549; (g) Filonenko, G. A.; van Putten, R.; Hensen, E. J. M.; Pidko, E. A., Catalytic (de)hydrogenation promoted by non-precious metals - $\mathrm{Co}, \mathrm{Fe}$ and $\mathrm{Mn}$ : recent advances in an emerging field. Chem. Soc. Rev. 2018, 47, 1459-1483; (h) Wang, Y.; Wang, M.; Li, Y.; Liu, Q., Homogeneous manganesecatalyzed hydrogenation and dehydrogenation reactions. Chem 2020, doi: 10.1016/j.chempr.2020.11.013; (i) Waiba, S.; Maji, B., Manganese Catalyzed Acceptorless Dehydrogenative Coupling Reactions. ChemCatChem 2020, 12, 1891-1902.

(21) (a) Brzozowska, A.; Azofra, L. M.; Zubar, V.; Atodiresei, I.; Cavallo, L.; Rueping, M.; El-Sepelgy, O., Highly Chemo- and Stereoselective Transfer Semihydrogenation of Alkynes Catalyzed by a Stable, Well-Defined Manganese(II) Complex. ACS Catal. 2018, 8, 4103-4109; (b) Freitag, F.; Irrgang, T.; Kempe, R., Mechanistic Studies of Hydride Transfer to Imines from a Highly Active and Chemoselective Manganate Catalyst. J. Am. Chem. Soc. 2019, 141, 11677-11685; (c) Ganguli, K.; Shee, S.; Panja, D.; Kundu, S., Cooperative Mn(i)-complex catalyzed transfer hydrogenation of ketones and imines. Dalton Trans. 2019, 48, 73587366; (d) Dubey, A.; Rahaman, S. M. W.; Fayzullin, R. R.; Khusnutdinova, J. R., Transfer Hydrogenation of Carbonyl Groups, Imines and N-Heterocycles Catalyzed by Simple, Bipyridine-Based MnI Complexes. ChemCatChem 2019, 11, 3844-3852; (e) Sklyaruk, J.; Zubar, V.; Borghs, J. C.; Rueping, M., Methanol as the Hydrogen Source in the Selective Transfer Hydrogenation of Alkynes Enabled by a Manganese Pincer Complex. Org. Lett. 2020, 22, 6067-6071.

(22) (a) Hirata, G.; Satomura, H.; Kumagae, H.; Shimizu, A.; Onodera, G.; Kimura, M., Direct Allylic Amination of Allylic Alcohol Catalyzed by Palladium Complex Bearing PhosphineBorane Ligand. Org. Lett. 2017, 19, 6148-6151; (b) Ghorai, S.; Chirke, S. S.; Xu, W.-B.; Chen, J.-F.; Li, C., Cobalt-Catalyzed Regio- and Enantioselective Allylic Amination. J. Am. Chem. Soc. 2019, 141, 11430-11434; (c) Lynch, C. C.; Balaraman, K.; Wolf, C., Catalytic Asymmetric Allylic Amination with Isatins, Sulfonamides, Imides, Amines, and N-Heterocycles. Org. Lett. 2020, 22, 3180-3184; (d) Harris, R. J.; Park, J.; Nelson, T. A. F.; Iqbal, N.; Salgueiro, D. C.; Bacsa, J.; MacBeth, C. E.; Baik, M.-H.; Blakey, S. B., The Mechanism of Rhodium-Catalyzed Allylic C-H Amination. J. Am. Chem. Soc. 2020, 142, 5842-5851; (e) Qu, J.; Helmchen, G., Applications of Iridium-Catalyzed Asymmetric Allylic Substitution Reactions in Target-Oriented Synthesis. Acc. Chem. Res. 2017, 50, 2539-2555.

(23) (a) Bäckvall, J.-E.; Andreasson, U., Ruthenium-catalyzed isomerization of allylic alcohols to saturated ketones. Tetrahedron Lett. 1993, 34, 5459-5462; (b) Uma, R.; Crévisy, C.; Grée, R., Transposition of Allylic Alcohols into Carbonyl Compounds Mediated by Transition Metal Complexes. Chem. Rev. 2003, 103, 27-52; (c) Crochet, P.; Díez, J.; Fernández-Zúmel, M. A.; Gimeno, J., Catalytic Isomerization of Allylic Alcohols by ( $\eta 6-p-C y m e n e)-$ Ruthenium(II) Complexes in Organic and Aqueous Media: New Recyclable and Highly Efficient Catalysts in Water Containing Ammonium-Functionalized Ligands. Adv. Synth. Catal. 2006, 348 , 93-100; (d) Mantilli, L.; Mazet, C., Iridium-catalyzed isomerization of primary allylic alcohols under mild reaction conditions. Tetrahedron Lett. 2009, 50, 4141-4144; (e) Slagbrand, T.;
Lundberg, H.; Adolfsson, H., Ruthenium-Catalyzed TandemIsomerization/Asymmetric Transfer Hydrogenation of Allylic Alcohols. Chem. Eur. J. 2014, 20, 16102-16106; (f) Cahard, D.; Gaillard, S.; Renaud, J.-L., Asymmetric isomerization of allylic alcohols. Tetrahedron Lett. 2015, 56, 6159-6169; (g) Vigneswaran, V.; MacMillan, S. N.; Lacy, D. C., $\beta$-Amino Phosphine Mn Catalysts for 1,4-Transfer Hydrogenation of Chalcones and Allylic Alcohol Isomerization. Organometallics 2019, 38, 4387-4391; (h) Cabré, A.; Garçon, M.; Gallen, A.; Grisoni, L.; Grabulosa, A.; Verdaguer, X.; Riera, A., Iridium-Catalyzed Asymmetric Isomerization of Primary Allylic Alcohols Using MaxPHOX Ligands: Experimental and Theoretical Study. ChemCatChem 2020, $12,4112-4120$.

(24) Grosser, T.; Ricciotti, E.; FitzGerald, G. A., The Cardiovascular Pharmacology of Nonsteroidal Anti-Inflammatory Drugs. Trends Pharmacol. Sci. 2017, 38, 733-748.

(25) Davies, N. M., Clinical Pharmacokinetics of Ibuprofen. Clin. Pharmacokinet. 1998, 34, 101-154.

(26) Seeman, P.; Lee, T.; Chau-Wong, M.; Wong, K., Antipsychotic drug doses and neuroleptic/dopamine receptors. Nature 1976, 261, 717-719.

(27) Eltze, M., Investigations on the mode of action of a new antihypertensive drug, urapidil, in the isolated rat vas deferens. Eur. J. Pharmacol. 1979, 59, 1-9.

(28) Cipriani, A.; Furukawa, T. A.; Salanti, G.; Chaimani, A.; Atkinson, L. Z.; Ogawa, Y.; Leucht, S.; Ruhe, H. G.; Turner, E. H.; Higgins, J. P. T.; Egger, M.; Takeshima, N.; Hayasaka, Y.; Imai, H.; Shinohara, K.; Tajika, A.; Ioannidis, J. P. A.; Geddes, J. R., Comparative efficacy and acceptability of 21 antidepressant drugs for the acute treatment of adults with major depressive disorder: a systematic review and network meta-analysis. Lancet. 2018, 391, 1357-1366.

(29) Ahmad, G., A Systematic Review of the Efficacy and Safety of Desipramine for Treating ADHD. Curr. Drug Saf. 2013, 8, 169174. 
SYNOPSIS TOC (Word Style “SN_Synopsis_TOC”).

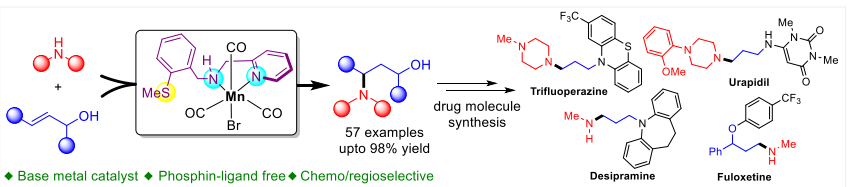

Insert Table of Contents artwork here 